\title{
Stable transfection system for Babesia sp. Xinjiang
}

\author{
Jinming Wang ${ }^{1 \dagger}$, Xiaoxing Wang ${ }^{1 \dagger}$, Guiquan Guan ${ }^{1 *}$, Jifei Yang ${ }^{1}$, Junlong Liu', Aihong Liu', Youquan Li', \\ Jianxun Luo ${ }^{1}$ and Hong Yin ${ }^{1,2^{*}}$
}

\begin{abstract}
Background: Stable transfection systems have been described in many protozoan parasites, including Plasmodium falciparum, Cryptosporidium parvum, Babesia bovis, Babesia ovata, and Babesia gibsoni. For Babesia sp. Xinjiang (Bxj), which is the causative pathogen of ovine babesiosis and mainly prevails across China, the platform of those techniques remains absent. Genetic manipulation techniques are powerful tools to enhance our knowledge on parasite biology, which may provide potential drug targets and diagnostic markers.

Methods: We evaluated the inhibition efficiency of blasticidin (BSD) and WR99210 to Bxj. Then, a plasmid was constructed bearing selectable marker BSD, green fluorescent protein (GFP) gene, and rhoptry-associated protein-1 3' terminator region ( $r a p 3^{\prime} T R$ ). The plasmid was integrated into the elongation factor-1 alpha (ef-1a) site of Bxj genome by cross-over homologous recombination technique. Twenty $\mu \mathrm{g}$ of plasmid was transfected into Bxj merozoites. Subsequently, drug selection was performed $24 \mathrm{~h}$ after transfection to generate transfected parasites.
\end{abstract}

Results: Transfected parasite lines, $B x j-c 1, B x j-c 2$, and $B x j-c 3$, were successfully obtained after transfection, drug selection, and colonization. Exogenous genes were integrated into the $B \times j$ genome, which were confirmed by PCR amplification and sequencing. In addition, results of western blot (WB) and indirect immunofluorescence assay (IFA) revealed that GFP-BSD had expressed for 11 months.

Conclusions: In our present study, stable transfection system for Bxj was successfully developed. We anticipate that this platform will greatly facilitate basic research of Bxj.

Keywords: Babesia sp. Xinjiang, Stable transfection, Genetic manipulation, Cross-over homologous recombination

\section{Background}

Babesiosis, caused by protozoan pathogens of the genus Babesia (phylum Apicomplexa, order Piroplasmida) infective to humans and domestic and wild animals, is one of the emerging and re-emerging tick-borne disease in tropical and subtropical regions of the world $[1,2]$. A

\footnotetext{
*Correspondence: guanguiquan@caas.cn; yinhong@caas.cn ${ }^{\dagger}$ Jinming Wang and Xiaoxing Wang contributed equally to this manuscript

${ }^{1}$ State Key Laboratory of Veterinary Etiological Biology, Key Laboratory of Veterinary Parasitology of Gansu Province, Lanzhou Veterinary Research Institute, Chinese Academy of Agricultural Science, Xujiaping 1, Lanzhou 730046, Gansu, China

Full list of author information is available at the end of the article
}

wide spectrum of clinical manifestation ranges from mild fever to serve anemia hemoglobinuria and even death [3]. Early in the nineteenth century, the first case of babesiosis was reported in Rumania and correlated with bovine hemoglobinuria or red water fever. Shortly after, similar organisms were also determined in sheep red blood cells [4]. Till now, more than 100 Babesia species have been described throughout the world. However, only a few Babesia species have been identified in sheep and cause ovine babesiosis, namely B. ovis, B. motasi, and B. crassa.

In China, ovine babesiosis was firstly reported as early as 1982 in Sichuan Province and 1986 in Heilongjiang Province $[5,6]$. Since then, this disease was sporadically reported in Xinjiang Uygur Autonomous region, Henan, original author(s) and the source, provide a link to the Creative Commons licence, and indicate if changes were made. The images or other third party material in this article are included in the article's Creative Commons licence, unless indicated otherwise in a credit line to the material. If material is not included in the article's Creative Commons licence and your intended use is not permitted by statutory regulation or exceeds the permitted use, you will need to obtain permission directly from the copyright holder. To view a copy of this licence, visit http://creativecommons.org/licenses/by/4.0/. The Creative Commons Public Domain Dedication waiver (http://creativeco mmons.org/publicdomain/zero/1.0/) applies to the data made available in this article, unless otherwise stated in a credit line to the data. 
Shannxi, Yunnan, and Hebei Province. During the past decades of investigations of ovine babesiosis, great attention had been paid to a novel Babesia species, Babesia sp. Xinjiang, which presented distinct morphologies from B. motasi, B. ovis, and B. crassa in a thin blood smear [7, 8]. This novel Babesia species was initially isolated from a splenectomized sheep infested with partially engorged Rhipicephalus sanguineus and Hyalomma anatolicum anatolicum ticks [9]. In the years since then, systematic

\section{Evaluation the inhibition efficiency of BSD and WR99210} to $B x j$

$B x j$ was cultured in complete medium with various concentrations of BSD $(1 \mu \mathrm{g} / \mathrm{ml}, 2 \mu \mathrm{g} / \mathrm{ml}, 5 \mu \mathrm{g} / \mathrm{ml}, 8 \mu \mathrm{g} / \mathrm{ml}$, and $10 \mu \mathrm{g} / \mathrm{ml})$ and WR99210 $(10 \mu \mathrm{g}, 25 \mu \mathrm{g} / \mathrm{ml}, 50 \mu \mathrm{g} / \mathrm{ml}$, $100 \mu \mathrm{g} / \mathrm{ml}$, and $200 \mu \mathrm{g} / \mathrm{ml}$ ), and the medium was replaced each day. The proportion of infected red blood cells (PI) was calculated by examining 2000 red blood cells (RBCs) stained with Giemsa in thin blood smear at $48 \mathrm{~h}$ [22]. The formula of $B x j$ growth inhibition was as follows:

(mean PI in control wells - mean PI in wells containing BSD) /mean PI in control wells $\times 100 \%$

studies of this Babesia species have investigated morphological characteristics, transmission patterns, culture features, epidemiology, pathogenicity, and whole-genome sequencing and annotation [10-14]. Available results indicated that this pathogen is widely distributed across China and has caused significantly economic losses to the sheep industry [15].

During recent decades, much attention has been focused on developing diagnostic assays and performing epidemiological investigations. However, available approaches to evaluate virulence factors and vaccine candidate antigens, and even to explore invasion and transmission mechanisms for these parasites, are limited. Ovine babesiosis control suffers from a lack of effective vaccines and limited choices of therapeutic drugs. Development of these relies on a better understanding of the basic biology of Babesia species [16]. Genetic manipulation technologies have been described to discover virulence factors and to investigate the interaction of parasite and host cells in apicomplexan parasites such as Cryptosporidium parvum, Babesia bovis, B. gibsoni, B. ovis, B. ovata, Theileria annulata, and T. parva [17-25]. In this study, we developed a stable transfection system of $B x j$ merozoites to investigate tick-Babesia and host-Babesia interactions in the future.

\section{Methods}

\section{In vitro culture system}

$B x j$ was cultured in 24-well plates (Corning, MA, USA) at $37^{\circ} \mathrm{C}$ under an atmosphere of $5 \% \mathrm{CO}_{2}$ as reported previously $[14,15,26]$. Briefly, the parasite was cultured in $7.5 \%$ fresh sheep erythrocytes supplemented with $20 \%$ fetal bovine serum (FBS) (Gibco, Carlsbad, CA, USA) in Roswell Park Memorial Institute 1640 medium (Lonza Biologics, Portsmouth, NH, USA).

\section{Plasmid constructs}

The plasmid construct used in this study is listed as Fig. 1 (PBS-bpgb-rap-orf). Initially, the ef1 $\alpha-B 5^{\prime}$ non-coding region and enhanced green fluorescent protein (eGFP) gene and blasticidin-S (BSD) deaminase gene were amplified from $B x j$ genomic DNA and plasmid $p g f p$-bsd-ef (kindly donated by Carlos E. Suarez) using the primer sets listed in Table 1. Then, these two sequences were cloned into the NotI site of plasmid pBluescript $\mathrm{SK}(+)$ using a ClonExpress MultiS One Step Cloning Kit (Vzayme, Nanjing, China) according to the manufacturer's instructions. This plasmid was designated as PBS-bpgb. Meanwhile, $B x j$ rap $3^{\prime}$ terminal region ( $B x j$ rap $3^{\prime}$ TR) and ef $1 \alpha-B$ open reading frame $(e f 1 \alpha-B$-orf $)$ sequences were amplified from $B x j$ genomic DNA and cloned into the NotI site of plasmid pBluescript $\mathrm{SK}(+)$ as mentioned above, and the generated plasmid was designated as PBS-TR-orf. Subsequently, the first large fragment of the ef1 $a-B$ non-coding region and $g f p$-bsd was amplified from plasmid $P B S$ $b p g b$, and the second fragment of the Bxj rap3' TR and ef $1 \alpha-B$ open reading frame sequences was derived from plasmid PBS-TR-ORF. Finally, these two large fragments were ligated into the NotI site of plasmid pBluescript

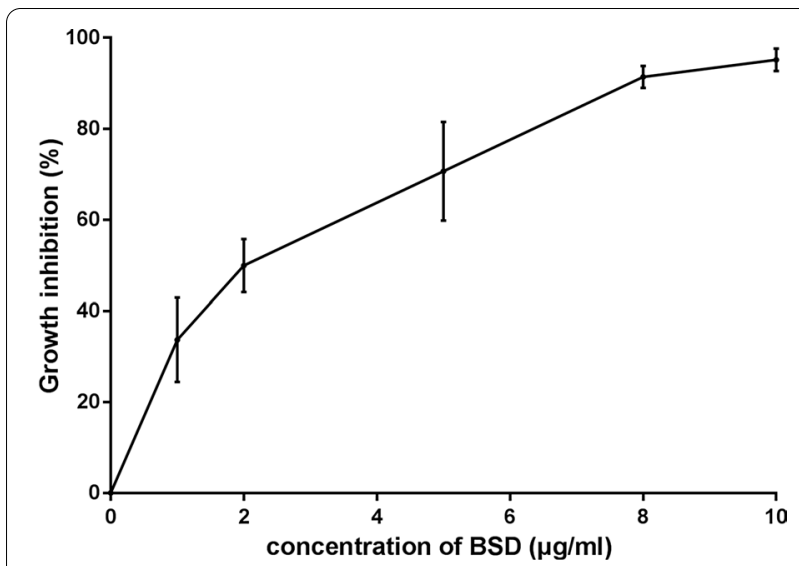

Fig. 1 Babesia sp. Xinjiang sensitivity to BSD. All data are presented as means \pm SD of triplicate cultures 
Table 1 Information of primer sets used in this study

\begin{tabular}{|c|c|c|c|}
\hline Gene & Sequence $\left(5^{\prime}-3^{\prime}\right)$ & $\begin{array}{l}\text { Size of target } \\
\text { sequence }\end{array}$ & Amplified fragment \\
\hline efla-B-F & ACTAGTTCTAGAGCGGCCGCGTTGTCTTTTGGTATTAC & 958 & efla- $B$ promoter sequence \\
\hline effa-B-R & CGCCCTTGCTCACCATTCTAGATTTCGTGGAGTTTTAACT & & \\
\hline$g f p-b s d-F$ & ATGGTGAGCAAGGGCGAGGAG & 1113 & gfp-bad gene \\
\hline gfp-bsd-R & AGCTCCACCGCGGTGGCGGCCGCTTAGCCCTCCCACACATAAC & & \\
\hline rap- $F$ & $\underline{\text { GGGAGGGCTAAGCGGCCGCGGCAGCTTCAAAGCG }}$ & 1362 & rap3'TR \\
\hline rap- $R$ & GGGTCTTCTCCTTCGGCATTCTTAACACCAGGCAAT & & \\
\hline efla-orf-F & ATGCCGAAGGAGAAGACCC & 1347 & effa-B orf \\
\hline ef2a-orf-R & CCGCGGTGGCGGCCGCTCACTTCTTGGCGGCCTTCTGGGC & & \\
\hline$e f b s-F$ & GAGCGTCGAATTATTAACTGGG & 1924 & F1 \\
\hline efbs- $R$ & CTTGTACAGCTCGTCCATGC & & \\
\hline gfor- $F$ & GCCAAGCCTTTGTCTCAAGAAG & 3394 & $\mathrm{~F} 2$ \\
\hline gfor- $R$ & CTAGCAGTGTGTTAGCGTGC & & \\
\hline orf- $R$ & GCACGATTCCATCGCTACAACG & 5960 & F3 (primer set efbs- $F$ and orf- \\
\hline
\end{tabular}

Homologous sequences are underlined and are employed to connect with upstream and downstream genes

SK(+), designated as PBS-bpgb-rap-orf. Furthermore, cloned plasmids were validated by polymerase chain reaction (PCR) amplification using two sets of primers (set 1: efla-B-F and ef1a-B-R; set 2: ef1a-orf-F and ef1aorf- $R$ ) and confirmed by sequencing and extracted using a QIAGEN Plasmid Maxi Kit (Qiagen, Hilden, Germany) according to the manufacturer's instructions.

\section{Electroporation of Bxj merozoites and drug selection}

When infected RBCs reached 10-20\%, the cultures in a $75 \mathrm{~cm}^{2}$ flask were centrifuged at $800 \times g$ for $10 \mathrm{~min}$. Then, the supernatant was removed, and cell pellets of Bxj-infected RBCs were washed twice in cold cytomix buffer $\left(120 \mathrm{mM} \mathrm{KCl}, 0.15 \mathrm{mM} \mathrm{CaCl}_{2}, 10 \mathrm{mM} \mathrm{K}_{2} \mathrm{HPO}_{4} /\right.$ $\mathrm{KH}_{2} \mathrm{PO}_{4}$, pH 7.6, 25 mM HEPES. pH 7.6, 2 mM EGTA, $5 \mathrm{mM} \mathrm{MgCl}_{2}$, final $\mathrm{pH}$ 7.6) [17, 18, 22, 27-29]. Mixture, containing $1 \times 10^{8}$ infected RBCs and $20 \mu \mathrm{g}$ of circular PBS-bpgb-rap-orf plasmid in a final volume of $100 \mu \mathrm{l}$ was transfected with parameters of $1200 \mathrm{~V}$ and $25 \mu \mathrm{F}$ using a Gene Pulser Xcell ${ }^{\mathrm{TM}}$ Electroporation System (Bio-Rad Laboratories, Hercules, CA, USA). After transfection, the mixtures were transferred into wells of 24-well culture plates containing $7.5 \%$ fresh sheep RBCs and 20\% FBS. After transfection for $24 \mathrm{~h}, 2 \mu \mathrm{g} / \mathrm{ml}$ of blasticidin-S (BSD, Gibco, R21001) was added to the cultures, and the concentration of BSD was gradually increased to $10 \mu \mathrm{g}$. Parasites, maintained in medium with BSD for 2-3 weeks, could be observed in thin blood smear stained with Giemsa under microscopy. To obtain a clonal strain, the population of parasites were diluted to 2.5 infected $\mathrm{RBCs} / \mathrm{ml}$ with completed medium containing $7.5 \%$ of fresh sheep RBCs. Then, $100 \mu \mathrm{l}$ of the diluted culture was added to each well of a 96-well culture plate, maintained at $37{ }^{\circ} \mathrm{C}$ in an atmosphere of $5 \% \mathrm{CO}_{2}$ for 14-17 days. During this period, the medium was completely replaced every 3 days. Three monoclonal strains were able to grow in a high concentration of BSD $(10 \mu \mathrm{g} / \mathrm{ml})$ and were designated as $B x j-c 1, B x j-c 2$, and $B x j-c 3$.

\section{Identification of monoclonal parasite $B x j$ stably expressing eGFP-BSD}

Three pairs of primer (Table 1 ) were designed to confirm whether the egfp-bsd-rap fragments were correctly integrated into the $B x j$ ef $1 \alpha$ locus. The first set of primers $(e f b s-F$ and $e f b s-R)$ was designed to amplify the F1 fragment with the size of 1924 bp to determine $5^{\prime}$ recombination, while the second set of primers ( $g$ for $-F$ and $g$ for $-R$ ) were generated to amplify the F2 fragment of $3394 \mathrm{bp}$ to confirm 3 ' recombination. Additionally, a large-size fragment (F3, $5960 \mathrm{bp}$ ) was amplified using the third primer pair (efbs-F and orf-R) targeting the ef1 $\alpha$ locus (Fig. 2).

To identify the expression of eGFP-BSD fusion protein, WB and indirect immunofluorescence assay (IFA) were performed. Briefly, when infected blood cells reached 5-10\%, cultures of $B x j-c 1, B x j-c 2, B x j-c 3$, and wild-type $B x j$ were added to three times the volume of red blood cell lysis buffer (Solarbio, Beijing, China) to lyse red blood cells. Merozoites of $B x j-c 1, B x j-c 2$, and $B x j$-c3 and wild-type $B x j$ (WT) were collected using centrifugation at $5000 \times g$ for $10 \mathrm{~min}$. The merozoite pellet was mixed with a twofold volume of $1 \mathrm{x}$ sodium dodecyl sulfate-polyacrylamide gel electrophoresis (SDS-PAGE) loading buffer and heated at $100{ }^{\circ} \mathrm{C}$ for $5 \mathrm{~min}$. Soluble proteins were subjected to SDS-PAGE and transferred to a polyvinylidene fluoride (PVDF) 


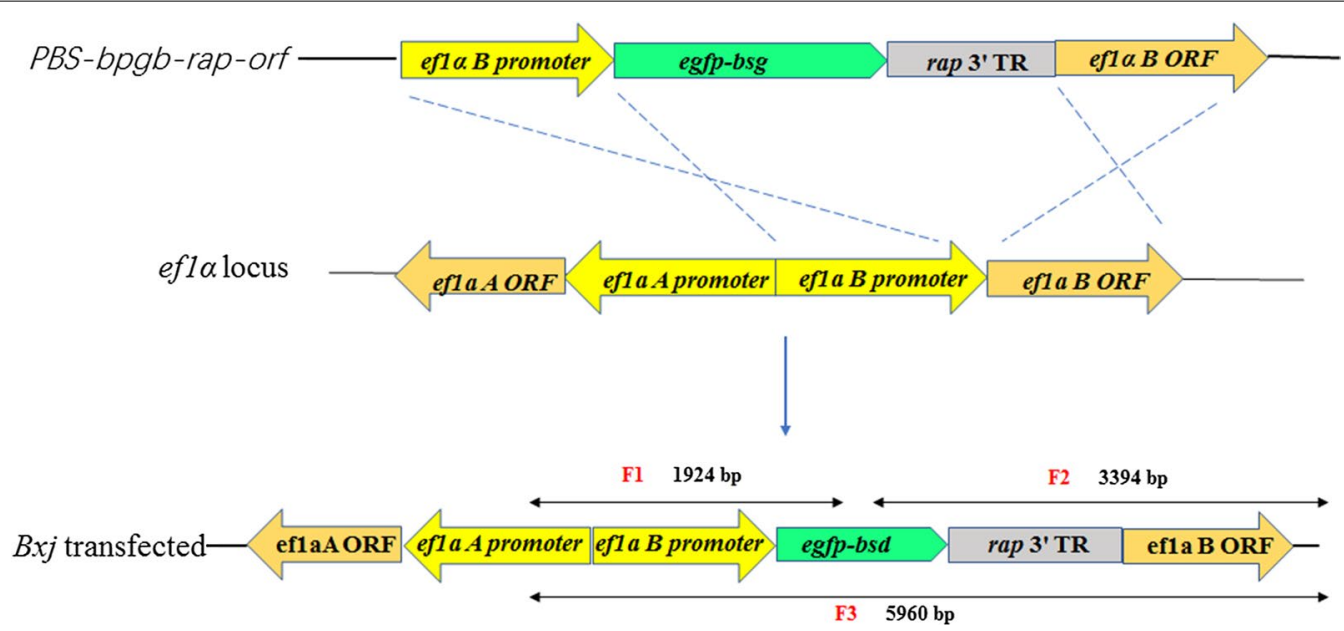

Fig. 2 Plasmid structures and ef1a locus in Bxj genome. PBS-bpgd-rap-orf shows the structure of plasmid used for stable transfection in this study. ef1 a locus illustrates the organization of ef1 $a$ in the Bxj genome. Transfected Bxj parasite lines, stably expressing eGFP-BSD fusion protein, should be like the Bxj transfected diagram

membrane. Then, the membrane was incubated with monoclonal anti-eGFP antibody (Sigma, SAB2702211, dilution: 1:2000) as the primary antibody followed with horseradish peroxidase (HRP)-conjugated goat anti-mouse IgG (Proteintech, USA, dilution: 1:5000), diluted with $0.1 \mathrm{M}$ Tris-buffered saline ( $\mathrm{pH}$ 7.6) with $0.1 \%$ Tween 20 (TBST). After the membranes were washed three times using TBST, bands were detected using a SuperSignal West Femto Kit (Thermo, USA) in a ChemiDoc MP imaging system (Bio-Rad, USA). IFA was performed using anti-GFP antibody (Sigma, SAB2702211, dilution: 1:200) as the primary antibody and Alexa 488-conjugated goat anti-mouse IgG (Thermo Fisher, USA, dilution: 1:500) as the secondary antibody [30]. The parasite nucleus was stained with Hoechst 33342 (Invitrogen, dilution: 1:2000) and observed with confocal laser scanning microscopy (SP8, Leica, Germany).

\section{Results}

\section{An inhibitory effect of BSD on Bxj merozoites in in vitro culture}

The inhibitory efficiency of BSD on $B x j$ merozoites in in vitro culture shows an upward trend with gradual increase of drug concentration, ranging from 1 to $10 \mu \mathrm{g} / \mathrm{ml}$ (Fig. 1). After $48 \mathrm{~h}$ of drug selection, the $50 \%$ inhibitory concentration of BSD $\left(\mathrm{IC}_{50}\right)$ was $2.26 \mu \mathrm{g} / \mathrm{ml}$. When the concentration reached $8 \mu \mathrm{g} / \mathrm{ml}$, the growth of over $90 \%$ of $B x j$ merozoites was inhibited. To inhibit the growth of WT, 2-10 $\mu \mathrm{g} / \mathrm{ml}$ BSD was employed in our following experiments.
Regarding the inhibition assays with WR99210, no efficient growth inhibition was observed. When the concentration of WR99210 increased to $150 \mu \mathrm{g} / \mathrm{ml}$, the growth inhibition of $B x j$ was as low as $\sim 30 \%$. Thus, the BSD gene was selected to be included in the following constructs as a selectable marker.

\section{Stable transfected $B x j$}

After 2 weeks of drug selection with BSD, transfected $B x j$ was cloned by limiting dilution. Three clonal parasite lines, designated as $B x j-\mathrm{c} 1, B x j-\mathrm{c} 2$, and $B x j-\mathrm{c} 3$, were obtained. At this point, no fluorescence was observed in the three lines. To determine whether the fragment of egfp-bsd-rap was correctly integrated into the target locus, PCR amplifications were performed using three primer pairs. As show in Figs. 2 and 3a, three fragments (1924, 3394, and $5960 \mathrm{bp}$ ) were successfully obtained from each of the parasite lines $(B x j-c 1, B x j-c 2$, and $B x j-c 3)$ and validated by gene sequencing. On the contrary, only one fragment (approximately $3500 \mathrm{bp}$ ), corresponding to the third primer pair, was amplified from WT (Fig. 3a).

\section{Expression analysis of eGFP-BSD fusion protein in Bxj merozoites}

Merozoites collected from $B x j-\mathrm{c} 1, B x j-\mathrm{c} 2, B x j-\mathrm{c} 3$, and WT were subjected to Western blot analysis to determine eGFP-BSD fusion protein (around $38 \mathrm{kDa}$ ) using monoclonal anti-eGFP. Available results showed that antibodies specifically bound to a protein of $\sim 38 \mathrm{kDa}$; however, they did not react with merozoite proteins of WT (Fig. 3b). Similarly, the evidence of IFA also 


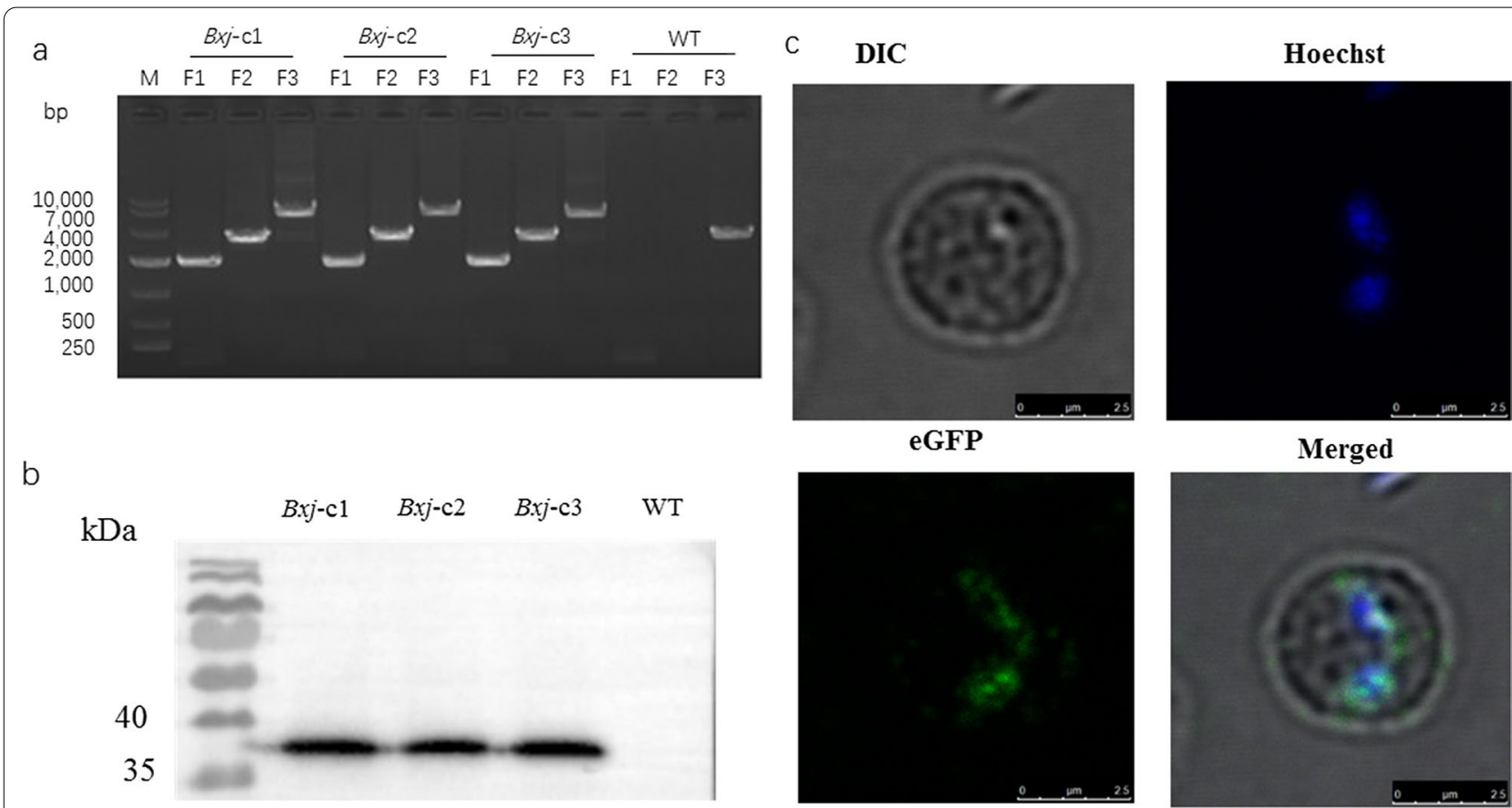

Fig. 3 Identification of monoclonal parasite Bxj stably expressing eGFP-BSD. a PCR amplification of F1, F2, and F3 fragments. b Western blot analysis of stable expression of eGFP-BSD in $B \times j-c 1, B x j-c 2$, and $B x j-c 3$. c IFA confirms stable eGFP expression of $B x j$. The parasite nucleus was stained with Hoechst 33342

demonstrated expression of eGFP-BSD in $B x j$ merozoites (Fig. 3c). These three lines stably expressed eGFP for 11 months.

\section{Discussion}

The first description of a stable transfection system in Babesia genus is reported in B. bovis in 2009; subsequently, this technique has been developed in B. gibsoni and $B$. ovata $[17,22,29]$. For most of public health/economically important Babesia spp., including B. microti, $B$. divergens, B. duncani, B. ovis, and Theileria spp., such as T. annulata and T. parva, genetic manipulation platforms have not been described. In addition, $B x j$ was firstly isolated from sheep infested with $R$. sanguineus and $H$. anatolicum anatolicum collected from the Xinjiang Uygur Autonomous Region in China in 2001 [31]. Prevalence of $B x j$ has been systematically investigated across China using molecular and sera techniques, such as multiplex PCR, loop-mediated isothermal amplification method, reverse line blot assay, and enzyme-linked immunosorbent assays $[11,12,15]$. Those data indicated that this pathogen was widely prevalent in sheep and goat in almost all investigated regions across China; however, genetic manipulation of $B x j$ has not been documented. In our previous study, we systematically evaluated the transient transfection parameters from
$B x j$, including transfection solution, programs, amount of plasmid DNA, and promoter activities. Eventually, a $B x j$ transient transfection system was developed with the most favorable transfection conditions (human $\mathrm{T}$ cell nucleoporation solution, program V-024, $20 \mu \mathrm{g}$ of plasmid DNA, and ef $1 \alpha$ promoter). However, an alternative transfection parameter (cytomix transfection solution, $1200 \mathrm{~V}$ and $25 \mu \mathrm{F}, 20 \mu \mathrm{g}$ of plasmid DNA, and ef $1 \alpha$ promoter) also achieved preferable results.

A drug selection marker is required to develop a stable transfection system for $B x j$. In this study, we firstly evaluated the sensitivity of $B x j$ to WR99210, which had been reported to provide suitable transfection of Plasmodium, $B$. bovis, and B. gibsoni. However, Bxj showed resistance to this drug. Similar situations have been described in $B$. bovis and Plasmodium spp. [17, 32]. This can be explained by the existence of an associated gene in the $B x j$ genome. Inhibition assays with BSD resulted in a strong $B x j$ merozoites growth inhibition with an $\mathrm{IC}_{50}$ of $2.26 \mu \mathrm{g} / \mathrm{ml}$, validating this drug as preferable to WR99210, the selection maker. Thus, this was the selection maker used for developing $B x j$ stable transfection. Nevertheless, it is worth mentioning that the value of $\mathrm{IC}_{50}$ is around five times of that B. bovis $(\sim 0.4 \mu \mathrm{g} / \mathrm{ml})$.

With regard to the target locus for genome integration, the ef1a locus was selected as the ideal target site for several Babesia spp., for instance B. bovis, B. ovata, 
and B. gibsoni $[17,22,29]$. Sequence analysis reveals that the Bxj ef1 $\alpha$ locus consists of two identical genes, arranged head to head and separated by a 1454-bp regulator sequence. Disruption one of these two genes had no significantly negative effect on survival and growth of parasites. It is suggested that this gene locus also serves as a suitable target site to introduce foreign genes for $B x j$. Transfected parasites could be observed under microscopy after 2 weeks of selection with BSD. PCR identification revealed that the fragment of $g f p$-bsd-rap 3' UTR was successfully introduced into the efl $\alpha$ locus of the cloned $B x j-c 1, B x j-c 2$, and $B x j-c 3$. Stably expressed eGFP was confirmed by WB and IFA assays; however, green fluorescence could not be observed with fluorescence microscopy. We attempted to obtain transfected $B x j$ which could directly detect fluorescence under fluorescence microscopy, by replacing the $e f-1 \alpha$ promoter with an actin promoter (approximately $2000 \mathrm{bp}$ )/ef1 $\alpha$-IG A and replacing eGFP with a red fluorescent protein gene (data not shown). However, this goal was not achieved. A similar situation was previously reported in C. parvum [19]. The firefly luciferase and fluorescent proteins were not detected in transfected parasites, whereas nanoluciferase showed significant reporter activity at $48 \mathrm{~h}$ after transfection [19].

Although there are still some drawbacks in this system, including lack of fluorescence and relatively low transfect efficiency compared with the CRISPR/Cas9-based genome editing strategy, this transfection system of $B x j$ provides a powerful tool to determine gene function and discover critical gene families of invasion, egress, immune evasion, and even virulence factors. A more convenient, facile, and highly effective technique needs to be developed in the near future.

\section{Conclusions}

To conclude, we provide a stable transfection system for $B x j$ and obtain transfected parasites, which have stably expressed eGFP-BSD for 11 months. This study is the first effort to create a platform for genetic manipulation of $B x j$ to further illustrate the invasive mechanism of this parasite, together with the parasite-vector and parasitehost interactions.

\section{Abbreviations \\ Bxj: Babesia sp. Xinjiang; FBS: Fetal bovine serum; RBCs: Red blood cells; PCR: Polymerase chain reaction; eGFP: Enhanced green fluorescent protein; BSD: Blasticidin; WB: Western blot; IFA: Indirect immunofluorescence assay.}

\section{Acknowledgements}

We acknowledged Carlos E. Suarez from the Department of Veterinary Microbiology and Pathology, Washington State University for technical supports and providing pgfp-bsd-ef and pBluescript SK(+) plasmid. The authors are grateful to Shin-ichiro Kawazu from the National Research Center for Protozoan
Diseases, Obihiro University of Agriculture and Veterinary Medicine, Obihiro, Hokkaido 080-8555, Japan, for providing DHFR-gfp plasmid.

\section{Authors' contributions}

JW and XW carried out the experiments. JW wrote the draft of the manuscript. $J Y, J L, A L$, and $Y L$ participated in plasmid construction. GG corrected the manuscript. JLu and HY supervised all parts of the study. All authors have read and approved the final manuscript.

\section{Funding}

This study was financially supported by the National Science Foundation of China (Grant No. 31972701), National Key Research and Development Program of China (Grant No. 2017YFD0501200), the 973 Program (Grant No. 2015CB150300), ASTIP (Grant No. CAAS-ASTIP-2016-LVRI), NBCIS (Grant No. CARS-37), and the Jiangsu Co-innovation Center Program for the Prevention and Control of Important Animal Infectious Disease and Zoonoses.

Availability of data and materials

All data are available upon request.

\section{Declarations}

\section{Ethics approval and consent to participate}

The study was approved by the Animal Ethics Committee of the Lanzhou Veterinary Research Institute, CAAS (Permit No. LVRIAEC-2018-001). All the procedures were conducted according to the Animal Ethics Procedures and Guidelines of the People's Republic of China.

\section{Consent for publication}

All authors consent to be published.

\section{Competing interests}

The authors declare no conflict of interest.

\section{Author details}

${ }^{1}$ State Key Laboratory of Veterinary Etiological Biology, Key Laboratory of Veterinary Parasitology of Gansu Province, Lanzhou Veterinary Research Institute, Chinese Academy of Agricultural Science, Xujiaping 1, Lanzhou 730046, Gansu, China. ${ }^{2}$ Jiangsu Co-Innovation Center for the Prevention and Control of Important Animal Infectious Disease and Zoonose, Yangzhou University, Yangzhou 225009, China.

Received: 5 January 2021 Accepted: 10 August 2021

Published online: 09 September 2021

\section{References}

1. Uilenberg G. International collaborative research: significance of tickborne hemoparasitic diseases to world animal health. Vet Parasitol. 1995;57:19-41.

2. Uilenberg G. Babesia-a historical overview. Vet Parasitol. 2006;138:3-10.

3. Yin H, Lu W, Luo J. Babesiosis in China. Trop Anim Health Prod. 1997;29(Suppl):11S-S15.

4. Babes V. Sur l'hémoglobinurie bactérienne du boeuf. C R Acad Sci. 1888;107:692-4.

5. Chen D. Investigation of ovine piroplasmosis. Chin J Vet SciTechnol. 1982;12:31-2.

6. Zhao X, Li C, Ming Y, Bai S, Chi S, Su G, et al. Investigation of ovine babesiosis. Chin J Vet Sci Technol. 1986;01:26-7.

7. Bai Q, Liu QY, Liu DK, Ren JX, Li X. Isolation and preliminary characterization of a large Babesia sp. from sheep and goats in the eastern part of Gansu Province, China. Parasitol Res. 2002;88:S16-21.

8. Yin H, Lu WS, Luo JX. Babesiosis in China. Trop Anim Health Prod. 1997;29:11s-s15.

9. Guan G, Ma M, Moreau E, Liu J, Lu B, Bai Q, et al. A new ovine Babesia species transmitted by Hyalomma anatolicum anatolicum. Exp Parasitol. 2009;122(4):261-7. 
10. Guan G, Korhonen PK, Young ND, Koehler AV, Wang T, Li Y, et al. Genomic resources for a unique, low-virulence Babesia taxon from China. Parasites Vectors. 2016;9:564.

11. Guan G, Chauvin A, Luo J, Inoue N, Moreau E, Liu Z, et al. The development and evaluation of a loop-mediated isothermal amplification (LAMP) method for detection of Babesia spp. infective to sheep and goats in China. Exp Parasitol. 2008;120:39-44.

12. Niu QL, Luo JX, Guan GQ, Liu ZJ, Ma ML, Liu AH, et al. Differentiation of two ovine Babesia based on the ribosomal DNA internal transcribed spacer (ITS) sequences. Exp Parasitol. 2009;121:64-8.

13. Wang X, Wang J, Liu J, Liu A, He X, Xiang Q, et al. Insights into the phylogenetic relationships and drug targets of Babesia isolates infective to small ruminants from the mitochondrial genomes. Parasites Vectors. 2020;13:378.

14. Guan G, Ma M, Liu A, Du P, Ren Q, Li Y, et al. Continuous in vitro cultivation of a recently identified Babesia that infects small ruminants in China. Vet Parasitol. 2012;187:3-4.

15. Guan G, Ma M, Liu A, Ren Q, Wang J, Yang J, et al. A recently identified ovine Babesia in China: serology and sero-epidemiology. Parasitol Int. 2012;61:532-7.

16. Antunes S, Rosa C, Couto J, Ferrolho J, Domingos A. Deciphering Babesiavector interactions. Front Cell Infect Microbiol. 2017;7:429.

17. Suarez CE, McElwain TF. Stable expression of a GFP-BSD fusion protein in Babesia bovis merozoites. Int J Parasitol. 2009:39:289-97.

18. Asada M, Tanaka M, Goto Y, Yokoyama N, Inoue N, Kawazu S. Stable expression of green fluorescent protein and targeted disruption of thioredoxin peroxidase-1 gene in Babesia bovis with the WR99210/dhfr selection system. Mol Biochem Parasitol. 2012;181:162-70.

19. Vinayak S, Pawlowic MC, Sateriale A, Brooks CF, Studstill CJ, Bar-Peled Y, et al. Genetic modification of the diarrhoeal pathogen Cryptosporidium parvum. Nature. 2015:523:477-80.

20. Adamson R, Lyons K, Sharrard M, Kinnaird J, Swan D, Graham S, et al. Transient transfection of Theileria annulata. Mol Biochem Parasitol. 2001;114:53-61.

21. De Goeyse I, Jansen F, Madder M, Hayashida K, Berkvens D, Dobbelaere $D$, et al. Transfection of live, tick derived sporozoites of the protozoan Apicomplexan parasite Theileria parva. Vet Parasitol. 2015;208:238-41.

22. Hakimi H, Yamagishi J, Kegawa Y, Kaneko O, Kawazu S, Asada M. Establishment of transient and stable transfection systems for Babesia ovata. Parasites Vectors. 2016;9:171.
23. Silva MG, Knowles DP, Suarez CE. Identification of interchangeable cross-species function of elongation factor-1 alpha promoters in Babesia bigemina and Babesia bovis. Parasites Vectors. 2016;9:576.

24. Liu M, Asada M, Cao S, Adjou Moumouni PF, Vudriko P, Efstratiou A, et al. Transient transfection of intraerythrocytic Babesia gibsoni using elongation factor-1 alpha promoter. Mol Biochem Parasitol. 2017;216:56-9.

25. Rosa C, Asada M, Hakimi H, Domingos A, Pimentel M, Antunes S. Transient transfection of Babesia ovis using heterologous promoters. Ticks Tick Borne Dis. 2019;10: 101279.

26. Guan GQ, Ma ML, Liu AH, Du PF, Ren QY, Li YQ, et al. Continuous in vitro cultivation of a recently identified Babesia that infects small ruminants in China. Vet Parasitol. 2012;187:371-8.

27. Suarez CE, McElwain TF. Transient transfection of purified Babesia bovis merozoites. Exp Parasitol. 2008;118:498-504.

28. Jaijyan DK, Govindasamy K, Singh J, Bhattacharya S, Singh AP. Establishment of a stable transfection method in Babesia microti and identification of a novel bidirectional promoter of Babesia microti. Sci Rep. 2020;10:15614

29. Liu M, Adjou Moumouni PF, Asada M, Hakimi H, Masatani T, Vudriko P, et al. Establishment of a stable transfection system for genetic manipulation of Babesia gibsoni. Parasites Vectors. 2018;11:260.

30. Qin M, Tang X, Yin G, Liu X, Suo J, Tao G, et al. Chicken IgY Fc expressed by Eimeria mitis enhances the immunogenicity of E. mitis. Parasites Vectors. 2016;9:164.

31. Guiquan G, Hong Y, Jianxun L, Wenshun L, Qicai Z, Milin M. Isolation of a large ovine Babesia sp. in Xinjiang, China. China J Vet Sci Technol. 2001;31:35-6.

32. Wang P, Wang Q, Sims PF, Hyde JE. Rapid positive selection of stable integrants following transfection of Plasmodium falciparum. Mol Biochem Parasitol. 2002;123:1-10

\section{Publisher's Note}

Springer Nature remains neutral with regard to jurisdictional claims in published maps and institutional affiliations.
Ready to submit your research? Choose BMC and benefit from:

- fast, convenient online submission

- thorough peer review by experienced researchers in your field

- rapid publication on acceptance

- support for research data, including large and complex data types

- gold Open Access which fosters wider collaboration and increased citations

- maximum visibility for your research: over $100 \mathrm{M}$ website views per year

At BMC, research is always in progress.

Learn more biomedcentral.com/submissions 